Revista Destaques Acadêmicos, Lajeado, v. 12, n. 2, 2020. ISSN 2176-3070

DOI: http://dx.doi.org/10.22410/issn.2176-3070.v12i2a2020.2582

http://www.univates.br/revistas

\title{
OS SINDICATOS NO BRASIL SOB A LUZ DA TEORIA DA "LÓGICA DA AÇÃO COLETIVA" DE MANCUR OLSON
}

\author{
Leonardo Rodrigues Ferreira ${ }^{1}$, Sandberg Marcel Santos ${ }^{2}$
}

Resumo: O presente trabalho trata da relação entre os sindicatos no Brasil e a teoria da lógica da ação coletiva de Mancur Olson, com enfoque na mudança na lei trabalhista de 2017: a contribuição sindical, que antes era obrigatória, passou a ser facultativa, gerando mudanças comportamentais nos sindicatos. O objetivo geral é estudar os sindicatos no Brasil, perante a teoria da lógica da ação coletiva, e os objetivos específicos são: identificar alguns elementos que expliquem como se dá o comportamento de grupos específicos, e analisar como esses elementos se interconectam ou se separam nas suas ideologias. Metodologicamente, o trabalho utiliza a teoria do programa, que é uma ferramenta de avaliação e análise das políticas públicas, consistindo em um constructo analítico entre meios e fins. Os resultados encontrados foram as mudanças realizadas pelos sindicatos para sobreviverem após a modificação da lei trabalhista. Foram verificadas ações mais atrativas para o associado, como serviços de saúde, assessoria jurídica e contábil, e ações voltadas ao lazer e à integração de seus membros, buscando, assim, manter a contribuição pecuniária de seus integrantes.

Palavras-chave: sindicatos, ação coletiva, grupos, teoria do programa.

\section{Introdução}

Em tempos de valorização da capacidade intelectual do homem, ao mesmo tempo que o trabalho em equipe é uma necessidade, devido à intensificação da fragmentação laboral, faz-se importante entender como é o trabalho em grupo e, principalmente, os conflitos entre interesses individuais versus interesses coletivos. Partindo dessa explanação, este artigo apresenta o seguinte problema: Como se comportam os sindicatos no Brasil, sob o ponto de vista da teoria da "lógica da ação coletiva" de Mancur Olson? O autor foi um economista e cientista social norte-americano, que trouxe em seu livro um estudo sobre o comportamento de grupos, e cuja tese aborda questões sobre as atitudes dos integrantes de um grupo. Nesse contexto, este trabalho apresenta

1 Doutorando em Ciência Política pela UFPE; e-mail: Irferreira.adm@gmail.com

2 Doutorando em Ciência Política pela UFPE; e-mail: sandbergms@gmail.com 
uma pesquisa sobre os sindicatos no Brasil sob a perspectiva e fundamentos do livro. Consequentemente, o objetivo geral é estudar os sindicatos no Brasil, perante a teoria da lógica da ação coletiva, e os objetivos específicos são identificar alguns elementos que expliquem como se dá o comportamento de grupos específicos, e como esses elementos se interconectam ou se separam nas suas ideologias. Esta pesquisa se justifica pela necessidade de se conhecer o perfil do indivíduo, quando está em um grupo que tem interesse comum, apesar de os seus interesses pessoais, muitas vezes, prevalecerem, em detrimento dos interesses coletivos. Em outra circunstância, até que ponto a pessoa contribui para o grupo e como se dá essa colaboração são perguntas que Olson (1999) procura responder. Além disso, ele dedica uma parte de seu livro "A lógica da ação coletiva" a falar do comportamento dos sindicatos, pois se trata de um grupo com várias peculiaridades grupais, nas quais os conflitos de interesses de grupos contra indivíduos são bastante acirrados, deixando à mostra batalhas de interesses. Este trabalho se limita a investigar a teoria de Olson (1999) nos sindicatos brasileiros, estudando os dilemas no desenvolvimento das atividades sindicais e, principalmente, discutindo sobre a credibilidade do sindicato para o trabalhador brasileiro.

\section{Referencial Teórico}

\subsection{Os Sindicatos no Brasil em números}

A Lei 11.648/2008 reconheceu formalmente as centrais sindicais no Brasil, enquanto entidades associativas de direito privado de representação geral dos trabalhadores, constituídas em âmbito nacional. No artigo primeiro da Lei 11.648/2008, estão definidas as atribuições e prerrogativas das centrais sindicais (BRITO FILHO, 2008).

Segundo dados do Ministério de Trabalho e Emprego (MTE), o Brasil tem 17.039 sindicatos com registro ativo. Desses, $11.706(68,70 \%)$ são de trabalhadores, e $5.333(31,30 \%)$ são de empregadores. Esses sindicatos patronais com registros ativos estão divididos em 3.642 (68,29\%) urbanos e 1.691 (31,71\%) rurais, informações geradas no dia 23 de outubro de 2019. Para fins de controle e verificação da representatividade, as centrais sindicais devem se cadastrar no sistema integrado de relações do trabalho (SIRT/MTE), devendo manter seus dados atualizados, conforme estabelecido no artigo $1^{\circ}$ da Portaria 194/2008 (MTE, 2019).

Diante dessas informações quantitativas, é possível observar alguns destaques no que diz respeito aos números sobre as centrais sindicais no Brasil. A Lei 13.467/2017 trouxe discussão referente à contribuição sindical, pois a "Lei da Reforma Trabalhista" sancionou o fim da contribuição obrigatória. Anteriormente à referida lei, era prevista, nos artigos 578 a 591 da Consolidação das Leis Trabalhistas (CLT), a obrigação compulsória do empregador de 
descontar da remuneração do empregado, no mês de abril de cada ano, o equivalente a um dia de trabalho por ano. O próprio empregador recolhia sua contribuição no mês de janeiro de cada ano. O propósito da cobrança era a manutenção das atividades sindicais e os valores eram destinados à "Conta Especial Emprego e Salário", que constitui os recursos do Fundo de Amparo ao Trabalhador-FAT. Contudo, depois da mudança da lei, o número de aberturas de sindicatos caiu significativamente (CLT, 2019).

Ao analisarmos os números sindicais no Brasil pelo ponto de vista da teoria do livro "A lógica da ação coletiva" de Olson (1999), é possível perceber que o comportamento dos indivíduos sindicalizados reflete o pensamento do autor, pois a obra tem como propósito esclarecer o comportamento de pessoas que se juntam para receber algum ganho coletivo.

\subsection{Os Sindicatos no Brasil e a Teoria da lógica da ação coletiva}

Como citado anteriormente, a contribuição obrigatória para os sindicatos passou a ser facultativa com a reforma trabalhista de 2017. Diante dessas circunstâncias, os sindicatos tiveram que buscar outros caminhos para a sua manutenção, que essencialmente tem a ver com o motivo da sua existência: o trabalhador e seus direitos laborais. Outras fontes de recursos são possíveis a centrais sindicais, tais como a atratividade para o contribuinte mensalista, com direito a assessoria jurídica, contábil, serviços de saúde, lazer entre outras vantagens. É interessante perceber que o objeto de estudo é o comportamento de indivíduos pensantes, que têm como finalidade a obtenção de vantagens coletivas que se convertam em benefícios individuais.

No desenvolvimento de seu argumento investigativo, Olson (1999) se manifesta na definição de benefício coletivo como um "benefício indivisível", ou seja, que, uma vez usufruído pelo grupo, não pode ser negado a um indivíduo desse grupo, mesmo que este não mereça a sua aquisição.

Partindo do pressuposto de que as pessoas que compõem um grupo não atuarão em busca de um objetivo comum, a menos que exista uma pressão, Olson (1999) justifica a ideia de que as atitudes coletivas não têm a mesma razão que direcionam as ações individuais. Analisando os grupos e as organizações, o teórico formou uma explicação técnica para o comportamento, estudando as consequências da sua aplicação em organizações de várias proporções. $\mathrm{O}$ autor pesquisou a teoria das classes sociais de Marx e a teoria dos grupos para demonstrar uma nova teoria dos grupos de pressão, na qual sugere que seu tamanho não deriva de seus êxitos, mas é subproduto de suas outras atividades.

É importante perceber que a tese proposta no livro "A lógica da ação coletiva" alerta para o conflito existente entre os interesses individuais e os coletivos, uma vez que o indivíduo busca primeiramente vantagens para si, e, a partir desse ponto, como ele irá conseguir essas vantagens, se sozinho ou com um grupo. 
Conforme Olson (1999), o interesse comum dos membros de um grupo pelo acesso a algum benefício coletivo nem sempre é suficiente para levar os membros a contribuir para a conquista desse benefício. Há casos em que o indivíduo do grupo, ciente de que o recurso coletivo não lhe será negado, independentemente de sua cooperação ou não, buscará se eximir, com o objetivo de evitar esforços, buscando o seu conforto, permitindo que os outros retribuam pelos dispêndios de sua conquista.

A escolha de toda pessoa racional sobre se irá ou não ajudar para conseguir algum benefício coletivo depende se os custos da ação forem menores do que os resultados alcançados. Olson (1999) menciona que grupos pequenos se inclinam a ter maior adesão de seus integrantes. Isso se dá por vários fatores, entre eles o fato de o ganho ser dividido por um número reduzido de componentes, sendo o resultado recebido relevante para cada membro. Para ele, grupos maiores são mais passíveis a não alcançarem seus objetivos, pois o benefício é distribuído de tal forma que os esforços da participação superam as vantagens obtidas, desalentando o indivíduo. Outra explicação se dá pela circunstância de que a não-colaboração do cidadão não reflete grande consequência sobre o resultado, o que normalmente não ocorre em grupos menores, onde existe uma maior dependência entre os membros para o êxito da ação. Grupos maiores tendem a ter pessoas não-colaborativas, mas que serão beneficiadas pelos resultados, uma vez que se trata de benefícios coletivos. Daí a necessidade de algum tipo de imposição sobre o não-participante, ou um benefício restrito para os componentes colaborativos. O centro do entendimento textual do autor é que a constituição de grupos, ou da atividade coletiva, se dá pela recompensa.

\subsection{A lógica da ação coletiva nos sindicatos}

Os sindicatos são representações organizadas de trabalhadores que buscam basicamente a aquisição de melhorias para a classe, a manutenção de direitos e o bem-estar de seus contribuintes. "A ação coletiva implica enfrentamento e defesa de interesses com direcionamento para ampliá-los do nível individual ao coletivo" (DE ARAÚJO, 2006).

De acordo com Olson (1999), sobre os sindicatos:

Dos sindicatos se espera que lutem por salários mais altos e melhores condições de trabalhos para seus afiliados; das organizações rurais espera-se que lutem por uma legislação favorável a seus membros; dos cartéis espera-se que lutem por preços mais altos para as empresas integrantes; das companhias espera-se que defendam os interesses de seus acionistas; e do Estado espera-se que promova os interesses comuns de seus cidadãos.

Os sindicatos são organizações através do qual os trabalhadores se juntam para obter salários mais altos no mercado e melhores condições de 
trabalho. As contribuições sindicais fornecem retribuições materiais individuais aos associados, tais como jornais, espaços de lazer e serviços de assistência jurídica e médica, exemplos que comprovam a necessidade da colaboração por parte do individuo sindicalizado. O custo de participar de um sindicato é significativo para o trabalhador individual (busca de informações sobre as questões que afetam a categoria; deslocamento para reuniões; tempo gasto em reuniões e outras atividades). Assim, o beneficiário (sindicalizado) deve perceber o benefício da sua participação em vantagens. Se ele não o identifica, não se credencia ao sindicato (OLSON, 1999).

A inclusão de um bem privado no processo de adesão ao sindicato é um motivo para uma mobilização exitosa que se encontra sob a forma de imposição (como a inscrição obrigatória em um sindicato) ou de oferta de incentivos que apenas os membros podem obter (DE ARAÚJO, 2006). A atitude adotada por Olson (1999) enfatiza que não é verdadeira a ideia de que os membros de um determinado grupo de interesses irão agir racionalmente para atingir determinado objetivo, e que nem todos os filiados aceitariam um consenso voluntário pelo bem comum.

A ação arbitraria é preponderante e totalmente lícita para o desenvolvimento de um sindicato. É muito difícil que trabalhadores dispersos, desmotivados e desorganizados criem ou mantenham um sindicato funcionando a contento. Por outro lado, um sindicato pequeno, mas bem estruturado, possui enormes chances de se tornar grande. A explicação se encontra no poder autoritário que as entidades exercem sobre seus filados (OLSON, 1999).

Buscando novas admissões de novos integrantes, os sindicatos utilizam de diferentes estratégias para atrair novos membros. Entre elas, a afiliação compulsória é o formato que tem mais eficácia. Outras formas são o próprio investimento no trabalhador, atrativos como descontos em produtos e serviços, entre outras. Até o momento em que as filiações eram obrigatórias, os sindicatos cresciam de forma exponencial. Após a lei da reforma trabalhista, que estabeleceu que as inscrições são facultativas, a arrecadação dos sindicatos caiu drasticamente (OLSON, 1999).

Alguns sindicatos no Brasil são muito ligados a grupos partidários, $\mathrm{o}$ que contribui para muitos entrarem e fazerem uso desse, com fins políticos. Nesse caso, a atividade fim da organização é muito prejudicada, porque o estabelecimento sindical vira palanque político, comprometendo a prestação de serviços para os membros da organização sindical. Os sindicatos promovem também um ganho político extremamente consistente, revelado pelo grande aumento do número de greves, que têm, muitas vezes, interesses suspeitos do ponto de vista político, econômico e social. 


\section{Metodologia}

A metodologia utilizada para a elaboração deste trabalho é do tipo qualitativa descritiva. Nela, irá se trabalhar com a extração dos dados qualitativos, para entender os fenômenos atribuídos ao objeto de estudo. $\mathrm{Na}$ pesquisa descritiva, realiza-se o estudo, a análise, o registro e a interpretação dos fatos do mundo físico, sem a interferência do pesquisador. $\mathrm{O}$ método descritivo se destina à identificação, registro e análise das características, fatores ou variáveis que se relacionam com as ocorrências ou fenômenos (GIL, 2008).

\subsection{Material e métodos}

Para realizar a análise dos dados, foi utilizada a teoria do programa, que é uma ferramenta de avaliação e análise das políticas públicas, e consistindo em um constructo analítico entre meios e fins. A teoria do programa se propõe a analisar quais recursos, atividades e estratégias precisam ser utilizados para se alcançar um determinado resultado em uma política. Ela tem como característica um conjunto de conjecturas que analisam como a política é relacionada com os seus benefícios sociais, e como ela produz meios para alcançar suas metas e objetivos. No caso específico dos sindicatos, serão utilizados os dados dos sindicatos de acordo com o cadastro no Ministério do Trabalho e Emprego (2019). Em seguida, será aplicada a teoria do programa, para avaliar sua eficiência organizacional (WORLD BANK, 2004).

\subsubsection{Teoria do programa: Modelo lógico}

O modelo lógico da teoria do programa foi desenvolvido pela Agência Americana para o desenvolvimento internacional, apresentando uma forma sistemática e visual para os componentes de um programa de política (FREITAS e SILVEIRA, 2015). Contudo, tal qualidade de ser essencialmente visual faz com que o modelo lógico proporcione que o avaliador identifique, dentro de seu programa, determinados componentes que irão contribuir na montagem das relações de causa e nos resultados do programa (ROSSI et al, 2003).

Quadro 1 - Síntese dos componentes do modelo lógico

\begin{tabular}{|l|l|}
\hline Componente & Definição \\
\hline Insumos & Recursos mobilizados em apoio às atividades \\
\hline Atividades & Ações realizadas a fim de alcançar os produtos \\
\hline Produtos & Resultante da transformação de insumos em resultados \\
\hline Resultados & Utilização do produto \\
\hline Resultados finais & Objetivos últimos do programa \\
\hline
\end{tabular}

Fonte: (DOMINGOS e SILVA, 2017) 
Conforme as explicações de Rossi et al. (2003), os elementos determinam os modos que se seguem. O componente de entrada (insumos) são todos os tipos de recursos, sejam humanos ou materiais, que foram direcionados para serem utilizados no programa. Entre os elementos (inputs), encontram-se tanto as pessoas (equipes) quanto a finalidade do orçamento disponível para o programa. As atividades são ações realizadas para produzir bens e serviços, com o propósito de transformar os insumos em produtos que sejam tangíveis ao público-alvo. Os produtos, portanto, são os resultados dessas ações. Melhor dizendo, são os resultados do processamento dos insumos em bens e serviços que são entregues no processo final do programa. Os resultados ou término do processo são a utilização dos produtos pelo usuário e, consequentemente, a obtenção dos objetivos finais do programa (ROSSI et al., 2003).

Quadro 2 - Síntese dos estágios na construção do modelo lógico

\begin{tabular}{|c|l|l|}
\hline Estágios & Procedimento & Como fazer? \\
\hline $\mathbf{1}$ & $\begin{array}{l}\text { Coleta de informações } \\
\text { importantes }\end{array}$ & $\begin{array}{l}\text { Survey/entrevistas com amostra do } \\
\text { público-alvo, análise documental }\end{array}$ \\
\hline $\mathbf{2}$ & Definir problema & Tomar conhecimento de causas e contexto \\
\hline $\mathbf{3}$ & $\begin{array}{l}\text { Preencher tabela com } \\
\text { elementos }\end{array}$ & $\begin{array}{l}\text { Dividir as informações coletadas no } \\
\text { estágio 1 e preenchê-las nos componentes } \\
\text { relativos a elas }\end{array}$ \\
\hline $\mathbf{4}$ & Desenho do modelo & $\begin{array}{l}\text { Inserir as linhas causais entre os } \\
\text { elementos dispostos no estágio 3 }\end{array}$ \\
\hline $\mathbf{5}$ & Verificação do modelo & $\begin{array}{l}\text { Conferir com os formuladores o resultado } \\
\text { do modelo }\end{array}$ \\
\hline
\end{tabular}

Fonte: (DOMINGOS e SILVA, 2017)

No primeiro estágio, a atividade prática deve ser elaborada com base nas informações sobre o público interessado do programa, apreciando o ambiente em busca de alterações que possam ter impactado o processamento do programa, além de verificar documentos relacionados. O segundo estágio, portanto, é a sustentação de toda a concepção do modelo: definição de um problema. É importante compreender os prováveis motivos do problema.

O terceiro estágio é o surgimento da estrutura do modelo lógico. Nessa fase, a equipe deve classificar as informações no formato de linhas e colunas em uma tabela, a fim de sistematizar o conhecimento sobre o programa. É necessário que se tenha o público definido do programa, todos os recursos que foram utilizados, as atividades que converteram os recursos em resultados concretos, os produtos resultantes das atividades implementadas, e os resultados primários e secundários (ROSSI et al, 2003). 
Figura 1 - Componentes do modelo lógico

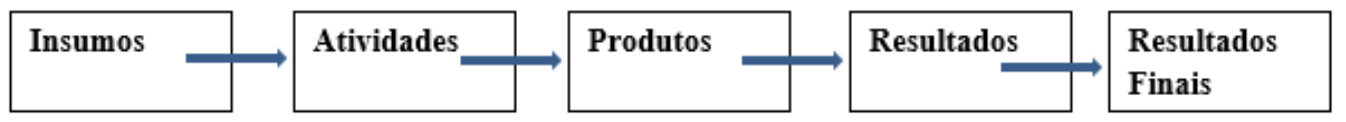

Fonte: (DOMINGOS e SILVA, 2017)

O quarto estágio conserva a realização do modelo lógico, onde se notam as associações de causa entre os elementos. Desse modo, o arranjo é habitualmente feito em um esquema de linhas e colunas, com palavras breves em caixas de texto e setas que simbolizam a relação de causa. As entradas (inputs) estarão na primeira coluna da esquerda e os resultados finais, na última da direita. A última fase é realizada com a equipe de trabalho que produziu o modelo e que deve analisar criticamente sua eficácia (Mclaughlin et al., 1999).

\section{Resultados e discussão}

Figura 2 -Modelo lógico dos sindicatos no Brasil em 2019

\begin{tabular}{|c|c|c|c|c|}
\hline Insumos & Atividades & Produtos & Resultados & Resultados \\
\hline $\begin{array}{l}\text { Registrar } \\
\text { (sindicalizar) } \\
\text { integrantes de } \\
\text { uma classe de } \\
\text { interesses } \\
\text { comuns, que } \\
\text { tenham objetivos } \\
\text { coletivos. }\end{array}$ & $\begin{array}{l}\text { Trazer melhorias } \\
\text { para os } \\
\text { sindicalizados, } \\
\text { promovendo } \\
\text { atividades } \\
\text { voltadas para o } \\
\text { lazer, saúde e } \\
\text { qualificação. }\end{array}$ & $\begin{array}{l}\text { Ganhos salariais } \\
\text { para os } \\
\text { sindicalizados, } \\
\text { plano de saúde, } \\
\text { auxilio- } \\
\text { educação, } \\
\text { auxilio-creche. }\end{array}$ & $\begin{array}{l}\text { Vantagens } \\
\text { significativas } \\
\text { para os } \\
\text { sindicalizados, } \\
\text { como convênios, } \\
\text { assessorias e } \\
\text { representação } \\
\text { profissional. }\end{array}$ & $\begin{array}{l}\text { Direitos e } \\
\text { produtos para os } \\
\text { sindicalizados. }\end{array}$ \\
\hline
\end{tabular}

Fonte: (DOMINGOS e SILVA, 2017)

De acordo com a Figura 2, pode-se identificar, de forma sucinta, o processo do modelo lógico dos sindicatos no Brasil em 2019. É interessante destacar principalmente os insumos (entradas) que têm como objetivo prospectar integrantes para o registro sindical, visto que a sobrevivência do sindicato vem principalmente da contribuição dos sindicalizados. Outro aspecto importante a ser evidenciado são os resultados, que devem ser atrativos para o público específico, uma vez que não basta apenas demonstrar uma representatividade da categoria; é necessário também apresentar vantagens interessantes para o integrante. 
Figura 3 - Referências básicas dos sindicatos no Brasil em 2019

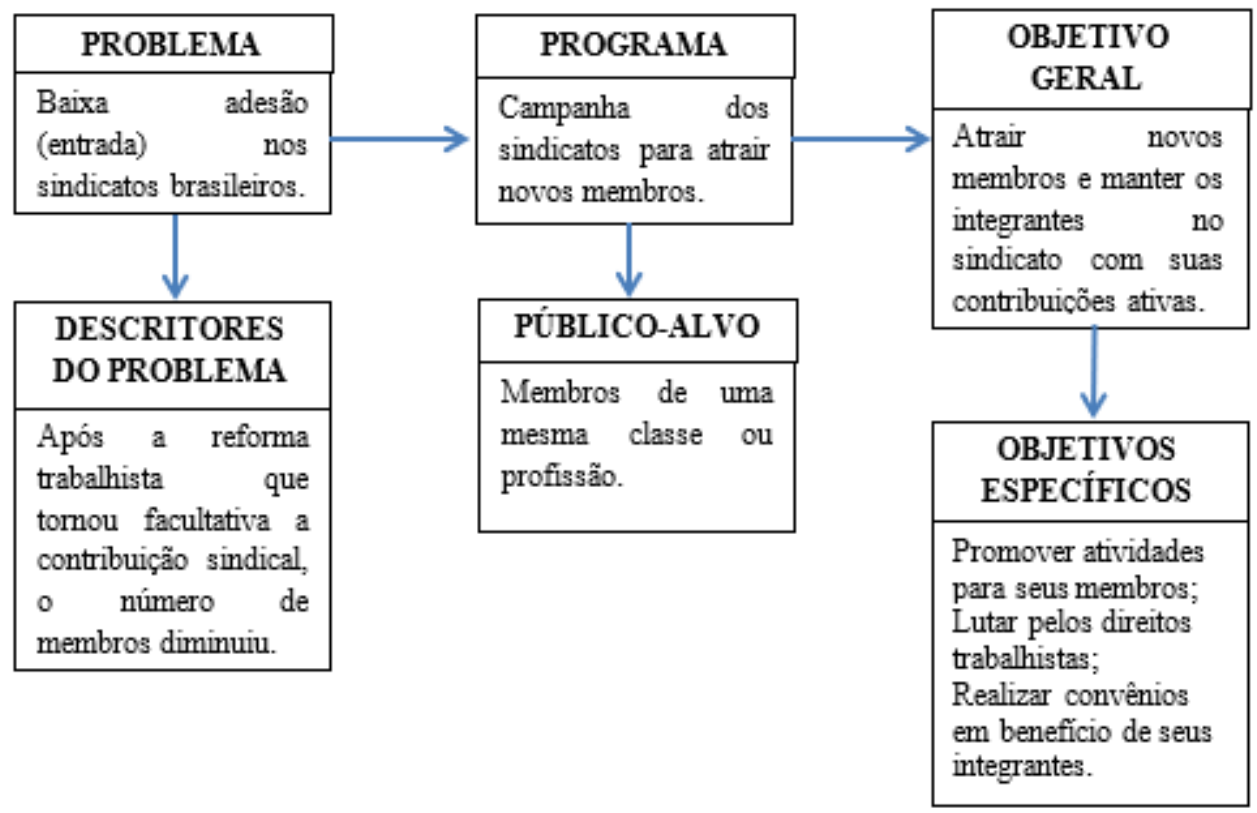

Fonte: autores (2019)

Conforme a Figura 3, verifica-se, em um processo simples do modelo lógico, o procedimento de avaliação de um programa de incentivo à sindicalização funcional. É importante destacar que houve uma particularidade: o processo de adesão sindical deve ser visto antes e depois da reforma trabalhista de 2017 (antes a contribuição era obrigatória e depois passou a ser facultativa). Após a mudança, os sindicatos no Brasil tiveram que se reinventar. Para manter e atrair novos membros, os sindicatos passaram a oferecer mais atrativos individuais e coletivos para os seus associados.

\section{Considerações Finais}

Com base nos remates da teoria do programa, este trabalho buscou avaliar a consistência investigativa e a relação de causa entre os sindicatos no Brasil e a teoria da lógica da ação coletiva de Mancur Olson (1999), a partir dos elementos oferecidos pelo modelo lógico de avaliação. Os resultados dos estudos apontam para uma mudança de comportamento dos sindicatos, corroborando a teoria de Olson (1999) sobre a lógica da ação coletiva, em que o indivíduo busca sempre por vantagens individuais, mesmo que esteja fazendo parte de um grupo.

As avaliações realizadas na pesquisa revelaram que o comportamento humano é condicionado aos interesses individuais e que, quando o sujeito busca a representatividade de forma coletiva, está convencido de que suas vantagens 
individuais serão aumentadas. Nessa busca por custo versus benefícios, está a entidade, ou seja, os sindicatos, que devem entender a lógica da ação coletiva, em que os interesses individuais prevalecem sobre os coletivos.

Em suma, o que os indivíduos querem é ter vantagens individuais, desprezando ideologias e representatividade. $\mathrm{O}$ que o sujeito busca em um sindicato, que é a representação da sua categoria profissional, são benefícios, ganhos ou proveitos na esfera individual e não-coletiva. Já os sindicatos precisam arrecadar para se manterem como organizações. O que se observa, no contexto atual, é o fim da arrecadação obrigatória dos sindicatos, que passou a ser facultativa, com o foco da associação sindical no seu membro, promovendo para o inscrito vantagens coletivas, com o objetivo de manter as suas contribuições.

\section{Referências}

BRITO FILHO, José Cláudio de. As Centrais Sindicais e a Lei N. 11.648/2008. Suplemento Trabalhista. Ano, 44.069: 2008.

DE ARAÚJO, Silvia Maria. Ação coletiva: equívocos interpretativos. INTERthesis: Revista Internacional Interdisciplinar, 2006, 3.1: 5.

DOMINGOS, Amanda; SILVA, Lucas E O., TEORIA DO PROGRAMA: O que é, para que serve e quando fazer? Anais do $9^{\circ}$ Congresso Latinoamericano de Ciência Política. 2017.

CONSOLIDAÇÃO DAS LEIS TRABALHISTAS - CLT. Disponível em:<http:/ /www. trt02.gov.br/geral/tribunal2/LEGIS/CLT/TITULOV.html> Acesso em: 29 out. 2019.

FREITAS, Gisele de; SILVEIRA, Suely de Fátima Ramos. Programa Luz Para Todos: uma representação da teoria do programa por meio do modelo lógico. Planejamento e Políticas Públicas, n. 45, 2015.

GIL, Antonio Carlos. Métodos e técnicas de pesquisa social. 6. ed. Editora Atlas SA, 2008.

MCLAUGHLIN, John A.; JORDAN, Gretchen B. Logic models: a tool for telling your programs performance story. Evaluation and program planning, v. 22, n. 1, p. 65-72, 1999.

MINISTÉRIO DO TRABALHO E EMPREGO - MTE. Sindicatos com registro ativo. Disponível em: <http://www3.mte.gov.br/sistemas/cnes/relatorios/painel/ GraficoTipo.asp > Acesso em: 29 out. 2019.

OLSON, Mancur; FERNANDEZ, Fábio. A lógica da ação coletiva: os benefícios públicos e uma teoria dos grupos sociais. Edusp, 1999. 
ROSSI, Peter H.; LIPSEY, Mark W.; FREEMAN, Howard E. Evaluation: A systematic approach. Sage publications, 2003.

WORLD BANK. Monitoring and evaluation: some tools, methods and approaches. Washington, 2004. 